Научная статья

УДК 332.1

DOI 10.18101/2304-4446-2020-4-84-91

\title{
РОЛЬ МУНИЦИПАЛИТЕТОВ В РЕАЛИЗАЦИИ СТРАТЕГИИ ПРОСТРАНСТВЕННОГО РАЗВИТИЯ
}

\author{
(C) Жалсараева Екатерина Александровна \\ кандидат экономических наук, доцент, \\ Восточно-Сибирский государственный университет технологий и управления \\ Россия, 670013, г. Улан-Удэ, ул. Ключевская, 40в \\ katya1e@yandex.ru
}

Благодарность: научная статья подготовлена при финансовой поддержке Российского фонда фундаментальных исследований (проект №19-010-00906А «Развитие теоретических подходов и разработка механизмов эффективного взаимодействия субъектов Байкальского макрорегиона в условиях пространственного развития»)

\begin{abstract}
Аннотация. В статье рассмотрены тенденции и современные проблемы развития муниципальной экономики в условиях пространственного развития территории. Муниципальный уровень экономики отличается существенной экономической дифференциацией между субъектами Российской Федерации. Цель исследования - определить роль и значение муниципалитетов в реализации принципов пространственного развития, определить основные проблемы, с которыми сталкивается муниципальное самоуправление в ходе реализации стратегических планов развития на основе оценки социально-экономического состояния. В качестве объекта рассматриваются муниципалитеты Республики Бурятия. Определены основные проблемные точки развития муниципальной экономической системы, в том числе несовершенство правовой базы, территориальная отдаленность, финансовая зависимость от вышестоящих уровней бюджета, несамостоятельность в принятии решений. Авторами определены приоритетные направления и даны рекомендации для развития потенциала муниципалитетов республики.
\end{abstract}

Ключевые слова: пространственное развитие; муниципалитет; территория; регион; дифференциация.

\section{Для цитирования}

Жалсараева Е. А. Роль муниципалитетов в реализации стратегии пространственного развития // Вестник Бурятского государственного университета. Экономика и менеджмент. 2020. № 4. С. 84-91.

В начале 2019 г. началась масштабная работа по реализации программы пространственного развития страны на основе принятой Стратегии пространственного развития. Данный документ определяет основные приоритеты государственной (федеральной) и региональной политики с учетом необходимости повысить темпы развития региональных экономик и преодоления дифференциации между ними. Основы такой политики закладывались в период реализации программы территориального планирования. По мнению ученых, российский подход к стратегическому планированию на уровне муниципальных образований имеет в своей основе ориентацию на достижение высокого уровня и качества 

вития

жизни населения в муниципальных образованиях, с последующим самообеспечением. Само по себе стратегическое планирование муниципального образования должно обеспечивать конкретизацию и достижение выбранных целей путем использования имеющихся преимуществ и создания новых, устанавливая связь между органами управления и населением, проживающим на данной территории для оптимального удовлетворения потребностей местного сообщества, общественного согласия [1].

Территория Российской Федерации обширна. Определяя значение муниципального уровня экономики, необходимо говорить о роли муниципалитетов как составляющей части региона, как об уровне территориального управления, чей статус был закреплен в Конституции РФ ${ }^{1}$. В условиях же пространственного развития главной задачей для муниципального уровня становится самореализация за счет имеющегося потенциала и выход на создание единого социальноэкономического пространства через преодоление экономической дифференциации.

В этой связи в качестве базовых точек роста для любого муниципалитета можно рассматривать, во-первых, уровень жизни населения (социальный, экологический, уровень образованности, обеспечение медицинскими и другими услугами и т. д.), во-вторых, уровень развития экономики муниципалитета (ресурсный потенциал, инфраструктура и объем финансовых ресурсов).

Эти и другие моменты рассматриваются во всех стратегических плановых документах регионов и страны в целом, а также в прогнозных вариантах развития территорий. Как правило, проекция их изучения сильно зависит от специфических особенностей самой территории муниципалитета (географических, климатических, культурных и др.).

В настоящее время в России насчитывается 20846 муниципальных образований различного вида, в том числе муниципальных районов - 1673, муниципальных округов - 33, городских округов - 632, городских округов с внутригородским делением - 3, внутригородских районов - 19, городских поселений - 1398, сельских поседений - 16821. Характеристика структуры системы муниципалитетов в РФ по округам представлена в таблице 1.

Таблица 1

Характеристика структуры системы муниципалитетов в РФ, по состоянию на 01.01.2020*

\begin{tabular}{|l|c|c|c|c|c|c|c|c|}
\hline & \multicolumn{7}{|c|}{ Муниципальные образования, в т. ч. } \\
\cline { 2 - 8 } & Всего & $\begin{array}{c}\text { Муници- } \\
\text { пальные } \\
\text { районы }\end{array}$ & $\begin{array}{c}\text { Муни- } \\
\text { ци- } \\
\text { паль- } \\
\text { ный } \\
\text { округ }\end{array}$ & $\begin{array}{c}\text { Город- } \\
\text { ские } \\
\text { округа }\end{array}$ & $\begin{array}{c}\text { Городской } \\
\text { округ с } \\
\text { внутри } \\
\text { городским } \\
\text { делением }\end{array}$ & $\begin{array}{c}\text { Внутри } \\
\text { Город- } \\
\text { ской } \\
\text { район }\end{array}$ & $\begin{array}{c}\text { Город- } \\
\text { ское } \\
\text { поселе- } \\
\text { ние }\end{array}$ & $\begin{array}{c}\text { Сельское } \\
\text { поселе- } \\
\text { ние }\end{array}$ \\
\hline $\begin{array}{l}\text { Российская } \\
\text { Федерация }\end{array}$ & 20846 & 1673 & 33 & 632 & 3 & 19 & 1398 & 16821 \\
\hline $\begin{array}{l}\text { Центральный } \\
\text { федеральный } \\
\text { округ }\end{array}$ & 4017 & 359 & 4 & 145 & & & 346 & 3017 \\
\hline
\end{tabular}

${ }^{1}$ Конституция РФ. Доступ из справ.-правовой системы «КонсультантПлюс». 


\begin{tabular}{|c|c|c|c|c|c|c|c|c|}
\hline $\begin{array}{l}\text { Северо- } \\
\text { Западный } \\
\text { федеральный } \\
\text { округ }\end{array}$ & 1390 & 143 & & 56 & & & 201 & 879 \\
\hline $\begin{array}{l}\text { Южный феде- } \\
\text { ральный округ }\end{array}$ & 1971 & 157 & & 41 & & & 96 & 1667 \\
\hline $\begin{array}{l}\text { Северо- } \\
\text { Кавказский } \\
\text { федеральный } \\
\text { округ }\end{array}$ & 1584 & 104 & & 39 & 1 & 3 & 30 & 1407 \\
\hline $\begin{array}{l}\text { Приволжский } \\
\text { федеральный } \\
\text { округ }\end{array}$ & 5441 & 404 & 13 & 104 & 1 & 9 & 302 & 4608 \\
\hline $\begin{array}{l}\text { Уральский } \\
\text { федеральный } \\
\text { округ }\end{array}$ & 1265 & 92 & & 110 & 1 & 7 & 77 & 978 \\
\hline $\begin{array}{l}\text { Сибирский } \\
\text { федеральный } \\
\text { округ }\end{array}$ & 3217 & 253 & 13 & 71 & & & 164 & 2716 \\
\hline $\begin{array}{l}\text { Дальнево- } \\
\text { сточный фе- } \\
\text { деральный } \\
\text { округ }\end{array}$ & 1961 & 161 & 3 & 66 & & & 182 & 1549 \\
\hline $\begin{array}{l}\text { Республика } \\
\text { Бурятия }\end{array}$ & 286 & 21 & & 2 & & & 16 & 247 \\
\hline $\begin{array}{l}\text { Республика } \\
\text { Саха (Якутия) }\end{array}$ & 445 & 34 & & 2 & & & 48 & 361 \\
\hline $\begin{array}{l}\text { Забайкальский } \\
\text { край }\end{array}$ & 410 & 31 & & 4 & & & 42 & 333 \\
\hline $\begin{array}{l}\text { Камчатский } \\
\text { край }\end{array}$ & 65 & 11 & & 3 & & & 4 & 47 \\
\hline $\begin{array}{l}\text { Приморский } \\
\text { край }\end{array}$ & 148 & 19 & 3 & 12 & & & 22 & 92 \\
\hline $\begin{array}{l}\text { Хабаровский } \\
\text { край }\end{array}$ & 232 & 17 & & 2 & & & 22 & 191 \\
\hline $\begin{array}{l}\text { Амурская об- } \\
\text { ласть }\end{array}$ & 285 & 20 & & 9 & & & 15 & 241 \\
\hline $\begin{array}{l}\text { Магаданская } \\
\text { область }\end{array}$ & 9 & & & 9 & & & & \\
\hline $\begin{array}{l}\text { Сахалинская } \\
\text { область }\end{array}$ & 18 & & & 18 & & & & \\
\hline $\begin{array}{l}\text { Еврейская } \\
\text { автономная } \\
\text { область }\end{array}$ & 33 & 5 & & 1 & & & 10 & 17 \\
\hline $\begin{array}{l}\text { Чукотский } \\
\text { автономный } \\
\text { округ }\end{array}$ & 30 & 3 & & 4 & & & 3 & 20 \\
\hline
\end{tabular}

* Составлено автором на основе данных Росстата ${ }^{1}$.

1 Формирование местного самоуправления в Российской Федерации [Электронный ре-
cypc]. URL: https://rosstat.gov.ru/folder/11110/document/13263 (дата обрашения: 10.10.2020). 
Е. А. Жалсараева. Роль муниципалитетов в реализации стратегии пространственного развития

В Республике Бурятия система муниципалитетов представлена 286 муниципальными образованиями, в том числе: 21 муниципальный район, 2 городских округа. Некоторые показатели социально-экономического развития муниципальных районов республики Бурятия представлены в таблице 2.

Таблица 2

Показатели социально-экономического развития муниципальных районов Республики Бурятия

\begin{tabular}{|c|c|c|c|c|c|}
\hline $\begin{array}{c}\text { Муниципальный } \\
\text { район }\end{array}$ & $\begin{array}{c}\text { Пло- } \\
\text { щадь, } \\
\text { км² }^{2}\end{array}$ & $\begin{array}{l}\text { Населе- } \\
\text { ние, чел. }\end{array}$ & $\begin{array}{l}\text { Среднемесяч- } \\
\text { ная заработная } \\
\text { плата, тыс. руб.. }\end{array}$ & $\begin{array}{c}\text { Доля нало- } \\
\text { говых и } \\
\text { неналого- } \\
\text { вых дохо- } \\
\text { дов местно- } \\
\text { го бюдже- } \\
\text { та** } \\
\end{array}$ & $\begin{array}{c}\text { Число субъектов } \\
\text { малого и среднего } \\
\text { предприниматель- } \\
\text { ства в расчете на } 10 \\
\text { тыс. чел. населения, } \\
\text { ед. }\end{array}$ \\
\hline $\begin{array}{l}\text { Городской округ } \\
\text { город Улан -Удэ }\end{array}$ & & 439128 & 43,8 & 38,2 & 453 \\
\hline $\begin{array}{l}\text { Городской округ } \\
\text { город Севе- } \\
\text { робайкальск }\end{array}$ & & 23183 & 63,9 & 34,5 & 395 \\
\hline Баргузинский & 18533 & 21516 & 35,4 & 21,1 & 261 \\
\hline $\begin{array}{l}\text { Баунтовский } \\
\text { эвенкийский }\end{array}$ & 66816 & 8454 & 58,8 & 23,3 & 320 \\
\hline Бичурский & 4491 & 22230 & 32,3 & 24,0 & 189 \\
\hline Джидинский & 8628 & 23388 & 30,7 & 13,5 & 156 \\
\hline Еравнинский & 25000 & 16585 & 34,4 & 16,6 & 181 \\
\hline Заиграевский & 6602 & 51387 & 36,6 & 23,7 & 221 \\
\hline Закаменский & 15345 & 25061 & 28,9 & 9,9 & 153 \\
\hline Иволгинский & 2068 & 59185 & 34,2 & 8,1 & 260 \\
\hline Кабанский & 13537 & 55468 & 34,4 & 29,0 & 244 \\
\hline Кижингинский & 7871 & 14464 & 29,3 & 10,9 & 243 \\
\hline Курумканский & 12491 & 13334 & 35,1 & 16,5 & 221 \\
\hline Кяхтинский & 4663 & 36538 & 33,0 & 32,1 & 169 \\
\hline Муйский & 25164 & 9548 & 76,0 & 28,4 & 455 \\
\hline $\begin{array}{l}\text { Мухоршибир- } \\
\text { ский }\end{array}$ & 4532 & 22856 & 43,8 & 31,6 & 207 \\
\hline
\end{tabular}




\begin{tabular}{|l|c|c|c|c|c|}
\hline Окинский & 26594 & 5452 & 53,7 & 24,9 & 199 \\
\hline Прибайкальский & 15472 & 26303 & 34,3 & 23,9 & 228 \\
\hline $\begin{array}{l}\text { Северо- } \\
\text { Байкальский }\end{array}$ & 53991 & 11301 & 61,8 & 15,5 & 312 \\
\hline Селенгинский & 8269 & 41274 & 38,6 & 16,1 & 251 \\
\hline Тарбагатайский & 3304 & 22419 & 33,3 & 17,1 & 195 \\
\hline Тункинский & 11800 & 20106 & 30,5 & 17,4 & 211 \\
\hline Хоринский & 13431 & 16757 & 30,7 & 21,3 & \\
\hline
\end{tabular}

Составлено автором на основе данных из источников ${ }^{1,2}$.

* Среднемесячная номинальная начисленная заработная плата работников крупных и средних предприятий и некоммерческих организации, тыс. руб. (в среднем по Республике Бурятия - 40,6 тыс. руб.)

**Доля налоговых и неналоговых доходов местного бюджета (за исключением поступлений по дополнительным нормативам отчислений) в общем объеме собственных доходов бюджета муниципального образования, \%

Из данных таблицы видно, что даже в одном регионе сильна дифференциация между муниципалитетами в зависимости от его величины (площади территории) и количества человек населения. По отраслевому признаку муниципальные районы Республики Бурятия можно разделить на несколько групп:

1. Районы с индустриальным вектором развития (Баунтовский эвенкийский, Муйский, Окинский районы). Здесь располагаются предприятия (хозяйствующие субъекты), занимающиеся разработкой месторождений минерально-сырьевых ресурсов: золота, молибдена, вольфрама, меди, урана, нефрита и др. В качестве примера можно назвать Кавоктинское месторождение в Баунтовском муниципальном районе, запасы нефрита которого составляют, по некоторым оценкам, порядка 1,3 тыс. т.

2. Районы с аграрным направлением (Бичурский, Еравнинский, Заиграевский, Закаменский, Кабанский, Мухоршибирский, Селенгинский и Хоринский районы, Джидинский и Кижингинский районы). Здесь реализуются все виды традиционного животноводства, а также развито земледелие, овощеводство.

3. Районы с приоритетным туристическим направлением развития (Баргузинский, Иволгинский, Курумканский, Кяхтинский, Прибайкальский, Тарбагатайский и Тункинский районы). Здесь определяющий фактор - привлекательность туристических объектов, в том числе религиозного значения - Иволгинский

${ }^{1}$ URL: http://www.statdata.ru/naselenie/respubliki-buryatiya (дата обращения: 12.10.2020).

2 Сводный доклад о результатах мониторинга эффективности деятельности органов местного самоуправления городских округов и муниципальных районов по итогам 2019 г. [Электронный ресурc]. URL: https://egov-buryatia.ru/minec/activities/directions/ strategicheskoe-upravlenie/ravitie-munitsipalnoy-ekonomiki/kompleksnaya-otsenka-ser-mo/ (дата обращения: 11.10.2020). 
дацан в Иволгинском муниципальном районе, святые места поклонения и наличие Забайкальского национального парка на территории Баргузинского муниципального района, курорты с минеральной водой в Тункинском муниципальном районе, побережье озера Байкал в Прибайкальском муниципальном районе.

Отдельно можно назвать группу городских округов - город Северобайкальск и город Улан-Удэ, их развитие определяется их статусом, а также наличием на территории промышленных объектов и высокой плотностью населения.

Учитывая отдаленность некоторых муниципальных образований от центра, необходимо отметить и некоторую оторванность от общих процессов, происходящих в экономике региона в целом. Именно поэтому важно учесть особенности развития муниципалитетов при создании центров развития, так называемых точек роста и сформировать на их основе эффективные в экономическом плане агломерации, что является одной из задач Стратегии пространственного развития РФ. В утвержденной в 2019 г. Стратегии пространственного развития РФ говорится о необходимости решения такой важной задачи, как снижение внутрирегиональных социально-экономических различий, в том числе за счет повышения устойчивости системы расселения путем социально-экономического развития городов и сельских территорий. Рассматривая данный вопрос применительно к районам Республики Бурятия, в первую очередь необходимо отметить неравномерность расселения на территории Республики Бурятия. Северные районы, характеризующиеся труднодоступностью, по вполне понятным причинам имеют низкий уровень постоянного населения (Муйский муниципальный район 9548 чел., Северо-Байкальский муниципальный район - 11301 чел., Окинский муниципальный район - 5452 чел.). В районах, находящихся в непосредственной близости к городам, численность населения значительно выше - в Иволгинском муниципальном районе - 59185 чел., Тарбагатайском муниципальном районе - 22419 чел., Кяхтинском муниципальном районе - 36538 чел. Миграция населения в такие районы связана с потребностями в постоянном месте работы, а также обусловливается более высоким уровнем обеспеченности медицинскими услугами и наличием образовательных учреждений.

Исходя из этого, для стимулирования развития муниципалитетов Республики Бурятия в целом можно определить ряд приоритетов для развития их экономического потенциала:

1. Совершенствование существующей нормативной базы для обеспечения большей взаимной согласованности и сбалансированности документов стратегического планирования, разрабатываемых на региональном и муниципальном уровнях. Например, доработка неэффективного законодательства для функционирования особо охраняемых природных территорий (ООПТ) в Тункинском районе Республики Бурятия. Границы административного района, муниципального образования практически полностью совпадают с границами Тункинского национального парка, что не позволяет применить к деятельности экономических субъектов в рамках Тункинского муниципального района законы без учета особого статуса территории, однако и нормативная база по функционированию ООПТ в этих условиях не работает [2]. 
2. Повышение степени федерального участия в методическом сопровождении стратегического планирования на муниципальном уровне, соблюдение принципа единства системы стратегического планирования в стране ${ }^{1}$.

3. Определение приоритетных направлений развития с учетом специфических особенностей муниципалитета, с учетом принципов рационального природопользования, особенно в тех районах Бурятии, где приоритетным направлением является сельское хозяйство. Введение инструментов экологической стандартизации и сертификации. Особое внимание следует обратить на наличие ООПТ федерального и регионального значения на территории муниципальных районов. Их площадь в Республике Бурятия составляет 3230 тыс. га, или 9,2\% общей площади региона. С точки зрения хозяйственного использования, начиная с 2000 г. ведутся научные дискуссии о введении понятия компенсационных выплат, например за поглощение углекислого газа территориями, покрытыми лесными и болотными угодьями, или использование водных ресурсов, сохраняя которые в качестве питьевых запасов, Байкальский макрорегион фактически отказывается от ведения промышленных разработок месторождений, и т. д. Несмотря на то, что данные предложения вполне обоснованы и, на наш взгляд, реализуемы, они до сих пор остаются нереализованными [2].

4. Повышение уровня вовлеченности местного населения в процессы стратегического планирования в муниципальных образованиях, стимулирование интереса и социальной ответственности населения.

5. Развитие сотрудничества на основе совместных интересов в муниципалитетах, чьи территориальные границы совпадают с границами страны. Зачастую приграничные муниципальные образования весь хозяйственный уклад ориентируют на взаимодействие с сопредельными странами, как это происходит в пределах Кяхтинского муниципального района, доходы бюджета которого формируются за счет приграничного сотрудничества с Монголией.

6. Реализация политики выравнивания уровней социально-экономического развития муниципальных образований, в том числе через прямое финансирование развития территории и создание благоприятного инвестиционного климата, вплоть до полного переориентирования экономики отдельно взятого муниципалитета на потенциальные возможности через внедрение инноваций (например, для муниципалитетов с индустриальным вектором - внедрение технологий энерго-и ресурсосбережения).

Таким образом, роль муниципалитетов в пространственном развитии страны очевидно высока. Муниципальные образования Республики Бурятия обладают высоким потенциалом развития, их можно рассматривать как стартовую площадку для реализации возможностей для региона в целом.

\footnotetext{
1 Сводный доклад о результатах мониторинга эффективности деятельности органов местного самоуправления городских округов и муниципальных районов по итогам 2019 г. [Электронный ресурс]. URL: https://egov-buryatia.ru/minec/activities/directions/ strategicheskoe-upravlenie/ravitie-munitsipalnoy-ekonomiki/kompleksnaya-otsenka-ser-mo/ (дата обращения: 11.10.2020).
} 
Литература

1. Стасишина Р. А. Экономические проблемы регионов и отраслевых комплексов // Проблемы современной экономики. 2010. № 2(34). С. 328-331.

2. Жалсараева Е. А. Эколого-экономические приоритеты пространственного развития региональной экономики как фактор национальной безопасности. Национальные приоритеты и безопасность: сб. науч. тр. по материалам междунар. науч.-практ. конф. Нальчик: Графика, 2020. С. 52-55.

\section{ROLE OF MUNICIPALITIES IN IMPLEMENTATION \\ OF THE SPATIAL DEVELOPMENT STRATEGY}

Ekaterina A. Zhalsaraeva

Cand. Sci. (Econ.), A/Prof.,

East-Siberian State University of Technology and Management

40v Klyuchevskaya St., Ulan-Ude 670013, Russia

katya1e@yandex.ru

Abstract. The article deals with the trends and contemporary development problems of the municipal economy in the context of spatial development. The municipal level of economy is characterized by significant economic differentiation between the constituent entities of the Russian Federation. The study identifies the role and importance of municipalities in the implementation of the principles of spatial development, the challenges faced by municipal self-government in implementing the strategic development plans based on evaluation of the socio-economic status. The municipalities of the Republic of Buryatia are objects of our research. We have identified the vulnerabilities of the municipal economic system, including the imperfection of legislation, territorial remoteness, financial dependence on higher authorities, and lack of independence in decision-making. Summing up, we have emphasized the priority areas and given recommendations for developing the potential of the republic's municipalities.

Keywords: spatial development; municipality; territory; region; differentiation.

Статья поступила в редакцию 21.10.2020; одобрена после рецензирования 30.10.2020; принята к публикации 30.10.2020. 